\title{
Automatic protray conveying and dibbling system towards development of automatic protray seeder for vegetable nursery
}

\section{A. Carolin Rathinakumari and G. Senthil Kumaran}

See end of the Paper for authors' affiliation

Correspondence to :

A. Carolin Rathinakumari ICAR-Indian Institute of Horticultural Research, Bengaluru (Karnataka) India

Email: carolin.rathinakumari@ gmail.com
-ABSTRACT : Quality and healthy seedling production is very important for successful vegetable cultivation. Recent days hybrid vegetable seedlings are raised in protrays under protected cultivation to ensure quality seedling production. Vegetable nursery raising is an upcoming successful entrepreneurship area. Growing media filled protrays are dibbled and seeded manually. This process is very tedious, labour intensive, time consuming and drudgery. Keeping this in view, an automatic protray conveying, dibbling and seeding system was designed and developed. The design and construction of automatic protray conveying and dibbling system is presented is this paper. The machine was designed suitable for 98 protray cell (Protray dimension : $530 \times 275 \mathrm{~mm}$ and protray cavity matrix: $14 \times 7$ (lengthwise $\mathrm{x}$ widthwise) which is widely used for vegetable nursery raising. This system consisted of protray conveyor and indexing system, dibbling unit, penumatic systems, electronic controls and programmable logic controller (PLC). The main conveyor shaft was driven by a stepper motor and the stepper motor was driven by a micro-stepping drive with $3200 \mathrm{pulse} / \mathrm{rev}$ configuration. Each protray was detected by a sensor and indexed by determined distance pre-programed of PLC. The function of dibbling unit was to make $10 \mathrm{~mm}$ dia. $\mathrm{x} 10 \mathrm{~mm}$ deep depressions at the center of the each cell of the growing media filled protray. The dibbling unit was a set of conically shaped tubular pegs arranged in a common bar. The stroke of the operation was $30 \mathrm{~mm}$ and indenting was $10 \mathrm{~mm}$ deep. Proximity sensor of PNP type was used for the dead end limits of all motions and conveyor index. The sensors used were dibbling station home sensor, dibbling station lower sensor, main conveyor indexing sensor and tray detection sensor. The entire cycle was controlled by a logic programme and this synchronized the conveyor motion (position/inching) with the dibbling system. This machine was able to index the growing media protrays at the predetermined distance of $38.3 \mathrm{~mm}$ and to make uniform depth cavities. The dibbling capacity was found to be 300 protrays $/ \mathrm{h}$.

KEY WORDS : Vegetable nursery, Step seeder, Automatic protray indexing, Crop nursery mechanization, Nursery machinery

-HOW TO CITE THIS PAPER : Rathinakumari,A. Carolin and Senthil Kumaran, G. (2020). Automatic protray conveying and dibbling system towards development of automatic protray seeder for vegetable nursery. Internat. J. Agric. Engg., 13(2) : 237-244, DOI: 10.15740/HAS/IJAE/13.2/237244. Copyright@2020: Hind Agri-Horticultural Society. 